\title{
MÍDIA, GOVERNAMENTO E MEIO AMBIENTE: PROVOCAÇÕES SOBRE EDUCAÇÃO AMBIENTAL
}

\author{
Lorena Santos da Silva ${ }^{1}$ \\ Paula Corrêa Henning ${ }^{2}$
}

\begin{abstract}
Resumo: O presente artigo segue sua linha da análise a partir do conceito de governamento presente nos estudos de Michel Foucault (2008). Como material empírico utiliza três propagandas circulantes na televisão brasileira e internet no primeiro trimestre de 2016. Campanhas de conscientização a favor da diminuição ou eliminação dos criadouros do mosquito Aedes aegypti. Tais artefatos midiáticos como produtores de saberes que ensinam e educam certos modos de agir, representar e relacionar-se com o meio ambiente. As considerações deste artigo enxergam no uso da estatística, dos saberes produzidos nos artefatos midiáticos legitimados pelo discurso científico, técnicas de governamento que incidem nas condutas e sentidos tomados como indispensáveis para a manutenção e bem-estar da população.
\end{abstract}

Palavras-chave: Pedagogia Cultural; Michel Foucault; Educação Ambiental.

\section{MEDIA, GOVERNMENTALITY AND THE ENVIRONMENT: PROVOCATIONS ON ENVIRONMENTAL EDUCATION}

\begin{abstract}
This paper follows the line of analysis based on the concept of governmentality found in the studies of Michel Foucault (2008). The empirical material uses the awareness campaigns of in favor of the diminution or elimination of Aedes aegypti mosquito breeding sites through the action of individuals in the environment are three advertisements that were broadcast on Brazilian television and internet in the first quarter of 2016. Such mediatic artifacts are as instruments that produce and circulate knowledge that teaches and educates certain ways of acting, representing and relating oneself with the environment. Our studies show the use of statistics, the knowledge produced in the mediatic artifacts legitimized by scientific discourses; techniques of governmentality that affect in the conduct and senses taken as indispensable for the maintenance and well-being of the population.
\end{abstract}

Keywords: Cultural Pedagogy; Michel Foucault; Environmental education.

\footnotetext{
${ }^{1}$ Graduada em Pedagogia pela Universidade Federal do Rio Grande - FURG e Mestranda no Programa de Pósgraduação em Educação Ambiental na Universidade Federal do Rio Grande - FURG. Bolsista Capes.

${ }^{2}$ Graduada em pedagogia pela Universidade Católica de Pelotas, Mestre em Educação pela Universidade Federal de Pelotas e Doutora em Educação pela Universidade do Vale do Rio dos Sinos. Professora Adjunta do Instituto de Educação, do Programa de Pós-graduação em Educação em Ciências e do Programa de Pós-graduação em Educação Ambiental da Universidade Federal do Rio Grande - FURG.
} 


\section{INTRODUÇÃO}

O mosquito Aedes aegypti não é novidade para os brasileiros, desde o final do século XX a dengue era considerada uma doença reemergente no país. Todavia tanto a dengue quanto a febre amarela são doenças já estudadas e compreendidas pela ciência. $\mathrm{O}$ aparecimento de doenças novas, como a chikungunya e a zika colocou o a população em estado de alerta.

Em especial a partir do ano de 2015 com o aparecimento de novas doenças associadas ao mesmo mosquito que transmite a dengue, parece ter surgido um esforço maior por parte das autoridades em produzir e disseminar saberes na mídia, convocando a população a engendrar-se na campanha nacional de erradicação dos criadouros do mosquito da dengue. Vemos que esta preocupação educativa explora demasiado os casos de bebês nascidos com microcefalia, após as mães terem sido diagnosticadas com o vírus zika durante a gravidez, para alertar a sociedade sobre a necessidade de agir no meio ambiente com o intuito de erradicar, ou pelo menos, reduzir os criadouros do mosquito vetor do vírus.

Por meio de artefatos culturais, como a mídia, somos constantemente alertados sobre os perigos eminentes à nossa segurança. Somos convocados a atuar na fiscalização de possíveis criadouros do mosquito, cuidando não só de nossa casa, mas também dos vizinhos e espaços públicos.

Neste trabalho tem-se concebido a mídia como uma ferramenta potente na circulação de diferentes temáticas. A presença midiática constante em espaços díspares caracteriza-a como uma estratégia de proliferação de informações e saberes. Um artefato cultural, que não apenas vem informando, mas nos ensinando determinados hábitos, valores e atitudes.

O campo dos Estudos Culturais é utilizado, aqui, a partir da visão de pesquisadores contemporâneos que se embasam na Virada Cultural do século XX em que a cultura é estudada a partir de suas finalidades produtivas presentes em aspectos sociais dos seres humanos. Analisando os caminhos históricos que deram condições para a emergência do conceito de cultura a partir do século XX é viável pensar que...

\footnotetext{
Essa centralidade da cultura - ressaltada entre tantos pesquisadores, por Stuart Hall, Fredric Jameson, Néstor Canclini, Beatriz Sarlo, David Havery - tem uma dimensão epistemológica, que vem sendo denominada "virada cultural", referindo-se a esse poder instituidor de que são dotados os discursos circulantes no circuito da cultura. Um noticiário da televisão, as imagens, gráficos etc. de um livro didático ou as músicas de um grupo de rock, por exemplo, não são apenas manifestações culturais. Eles são artefatos produtivos, são práticas de representação, inventam sentidos que circulam e operam nas arenas culturais onde o significado e as hierarquias são estabelecidas (COSTA, SILVEIRA \& SOMMER, 2003, p. 38) [grifo no original]
} 
A partir da expansão das ações da cultura, os Estudos Culturais permeiam transversalmente por áreas do conhecimento já estabelecidas. Consequentemente na heterogeneidade teórica e metodológica os Estudos Culturais atravessam uma vasta variedade de campos buscando romper com a lógica linear, problematizando as relações de poder imbricadas às práticas culturais em sua complexidade contextual sócio-política em que a cultura torna-se objeto de análise e crítica.

Esta pesquisa não tem por objetivo desqualificar ou refutar os saberes transmitidos nos meios midiáticos, ao contrário, busca-se olhar para as campanhas publicitárias contra a proliferação do mosquito da dengue a partir de sua produtividade educativa. Na esteira da Educação Ambiental, compreende-se a mídia como uma das ferramentas que circulam saberes ensinando aos sujeitos atitudes que incidem no meio ambiente.

A multiplicidade de espaços de aprendizagens e saberes fabricados é concebida, neste artigo, nos atravessamentos de estratégias de poder que se vale de procedimentos, análises e cálculos que permitem exercer a governamentalidade, a partir de algumas técnicas de governamento da população dentro de uma sociedade de múltiplas aprendizagens.

Utiliza-se o neologismo foucaultiano gounernementalité, por entender que na língua portuguesa não há palavra que a traduza, que se designe a significar governamentalidade em sua ampliação e utilização, pelo Estado, na qualidade de determinadas técnicas de governo para sua própria manutenção. Para a utilização deste conceito deve-se ter claro de que não se trata de uma característica, nem de abordar os atributos de algo ou alguém em deixar-se governar. Entender o processo da governamentalidade, portanto, resulta em conceber a existência de "[...] um novo tipo de Estado, o Estado moderno, o Estado governamental" (VEIGA-NETO, 2005, p. 32).

A ideia de governamentalidade discutida por Michel Foucault (2008) carrega em si a construção de um conceito de população que necessita ser governada no interesse individual e coletivo. Esse governamento a que se refere o autor foi possível a partir da constituição de uma ciência política que definiu a necessidade de gerenciar a condução da vida da população, como domínio de intervenção e objeto de governo. O poder exercido conforme o modelo da economia foi possível:

[...] com o desenvolvimento dessa ciência do governo que se pôde isolar os problemas específicos da população; mas também se pode dizer que foi graças à percepção dos problemas específicos da população, graças ao isolamento desse nível de realidade, que chamamos a economia, que o problema do governo pôde enfim ser pensado, sistematizado e calculado fora do quadro jurídico da soberania (FOUCAULT, 2015, p. 423). 
Pensando na mídia como uma Pedagogia Cultural, os artefatos culturais estão sendo compreendidos como tecnologias que disseminam saberes aceitos, em certos casos, como verdadeiros (WORTMANN, 2004). A aprendizagem midiática possui em si, certa uniformidade enunciativa. O que é dito em uma campanha publicitária referente a uma empresa que se coloca como preocupada com as questões da dengue é fabricada nas mesmas regularidades enunciativas que a propaganda financiada pelo Governo Federal. Na positividade das enunciações midiáticas busca-se analisá-las como instrumento que tornam visíveis as técnicas de governamento.

Tendo como corpus analítico três propagandas circulantes na televisão e internet no primeiro trimestre de 2016, sendo que destas, uma é produto de uma empresa do setor privado, outra do Ministério da Educação e a última do Ministério da Saúde, assumimos a postura de analisá-las, partindo do acento pós-estruturalista vinculado aos Estudos Culturais. O material empírico é analisado na qualidade de artefato cultural que coloca em funcionamento parte de uma Pedagogia Cultural ${ }^{3}$ que objetiva ensinar e educar os sujeitos para além da institucionalização escolar. Sua intenção baseia-se na busca por propagar determinados modos de ser, pensar e agir na sociedade e no ambiente.

As medidas preventivas contra a proliferação do Aedes aegypti anunciadas nas campanhas publicitárias analisadas são vistas enquanto manifestações de saberes que circulam verdades produzidas. Estamos constantemente aprendendo em diferentes espaços e artefatos. Na pluralização de saberes e aprendizagens, é que se embasam as problematizações trazidas neste artigo.

Em uma consideração breve, reconhece-se nas campanhas publicitárias informações sobre a urgência social de combate ao mosquito que colocam em circulação alguns saberes que incidem sobre as atitudes dos seres humanos no ambiente, mesmo que sob a égide da preocupação com a vida humana. Pensar as relações com a Educação Ambiental, assim, tratase de operar com as interações socioambientais ainda que marcadas por um acento antropocêntrico em que o cuidado com o ambiental se dá por meio da centralidade do ser humano.

O presente artigo provoca pensar as relações socioambientais propagadas na mídia por meio da preocupação com o controle da saúde humana. Entende-se, por conseguinte, que os

\footnotetext{
${ }^{3} \mathrm{O}$ termo Pedagogia Cultural marca a articulação entre dos processos educativos às relações culturais, uma vez que expandi a compreensão da pedagogia para diversas dimensões da vida que não se resumem aos espaços educativos (ANDRADE \& COSTA, 2015).
} 
saberes produzidos e circulantes na mídia operam junto de uma rede mais complexas de saberes e poderes para entrar em funcionamento incidido na fabricação dos modos de relacionar-se com o meio ambiente sejam através da individualidade de cada sujeito ou na coletividade da população. Sob esse viés é que nos debruçaremos com maior ênfase.

As propagandas que apresentam visões sobre meio ambiente, em relação com a Educação Ambiental, disseminam saberes para além de uma ciência puramente ecológica. Tais representações, postas em circulação, nos mais diversos veículos midiáticos, são produzidas nas/pelas interações ecossistêmicas e socioculturais. Para embasar este direcionamento de olhar do campo, utilizo as concepções de Félix Guattari (2012), no que concerne a articulação ético-política entre o meio ambiente, as relações sociais e as subjetividades humanas.

Apresentando a proposta das três ecologias (social, mental e a da subjetividade humana) o autor defende que as invenções tecnológicas e científicas, atualmente em grande crescimento devido à intensa narrativa contemporânea acerca de uma crise ambiental, são instrumentos que atuam na exterioridade das subjetivações, ou seja, não atingem os modos de nós, seres humanos, convivermos com nosso Planeta. Por isso, Félix Guattari (2012) insiste em uma proposta ecosófica em que os componentes éticos, políticos, sociais e estéticos presentes na Educação Ambiental, são componentes que operam na subjetivação, ou como traz o autor na "ressigularização" (IDEM, p. 55), dos sujeitos em sua particularidade e coletividade.

Uma ciência da relação entre ser humano e meio ambiente, articula a Educação Ambiental às interações entre o dito ambiental e o dito cultural. Há certa correlação na constituição do que é ambiental e do que é cultural, já que os significados e conceitos, que se apresentam em relação ao meio ambiente e à natureza, são advindos de construções culturais que se definem nessa interação. Nessa correnteza Marcos Reigota (2014, p.36) define meio ambiente como “[...] um lugar determinado e/ou percebido onde estão em relação dinâmica e em constante interação os aspectos naturais e sociais. Essas relações acarretam processos de criação cultural e tecnológica e processos históricos e políticos de transformação da natureza e da sociedade." Perante tal elucidação o meio ambiente não se constitui fora da sociedade, assim como essa, igualmente, é interpelada pelos aspectos ambientais.

A disseminação de representações, saberes, formas de atuarmos sobre o meio ambiente presentes nos artefatos midiáticos analisados são produtores das concepções que, na 
maioria das vezes, aceitamos como nossas. As propagandas, assim, são entendidas enquanto ferramentas que disseminam determinadas ações no meio ambiente para a erradicação do mosquito Aedes aegypti, como meio de preservar a segurança da população e a manutenção do Estado nas minúcias da verdade científica e da conscientização coletiva.

$\mathrm{Na}$ linha deste artigo nos propomos a pensar a Educação Ambiental nos atravessamentos dos estudos pós-estruturalistas, no entendimento de que precisamos dar visibilidade para a multiplicidade de espaços e artefatos que produzem saberes acerca da natureza, saúde, bem estar e segurança. Procuramos assim, “[...] provocar o pensamento, de compor resistências e criações diante de discursos instaurados como verdadeiros neste tempo em que consolida uma forma de ser, viver e sentir a educação ambiental" (HENNING, 2012, p. 242).

Partindo das inquietações e problematizações tecidas de maneira introdutória até o momento, passamos na seção seguinte a discutir as práticas de governamento da população por meio dos saberes produzidos e veiculados nas propagandas que alertam e convidam a sociedade para agir no meio ambiente como garantia de proteção da saúde contra os vírus transmitidos pelo mosquito Aedes aegypti. Problematizações, essas, previamente encerradas nas considerações finais, com a clareza e o cuidado de compreender que os saberes produzidos nas propagandas estão situados nos acontecimentos históricos que redirecionaram os discursos sobre o Aedes aegypti para outras regularidades. Sobre a produtividade educativa das propagandas em formar modos de convidar a população a agir no meio ambiente é que trataremos a seguir.

\section{A RELAÇÃo COM O MEIO AMbiente VISTA ENQUANTO PRÁtica de GOVERNAMENTO DA POPULAÇÃO}

A ênfase política deste artigo busca desmembrar o artefato cultural selecionado para mostrar como a mídia tem contribuído para a regulamentação de determinadas condutas dos sujeitos perante o meio ambiente com o interesse de ensiná-los e educá-los a partir da seleção do que é dito como necessário para o bem-estar coletivo. A pretensão que temos é a de mapear algumas aprendizagens sobre Educação Ambiental que acontecem em espaços não institucionalizados e operam como técnicas de governamento da população.

As mídias sejam voltadas à conscientização, à comercialização ou ao entretenimento das pessoas ensinam modos de vida, produzindo subjetividades. Nesse sentido, a mídia tem sido propagadora de significados e representações compartilhadas no contexto sociocultural. 
A agilidade com que propaga as informações e sua presença em diferentes momentos do cotidiano são atributos que mostram sua potência na posição de instrumento que possibilita a produção de sentidos que nos atravessam.

Por meio da concepção de Pedagogia Cultural se enfatiza que o processo educativo ocorre em uma variedade de espaços sociais que incluem a escola, mas não se resumem a ela. Contudo pensar atualmente em múltiplos espaços de aprendizagens só é viável porque os conceitos de pedagogia e educação estão de acordo com o que é inteligível na ordem do discurso. Permitindo a constituição da compreensão de educação como condição imprescindível para a humanização de cada indivíduo e para a boa convivência em sociedade. Entende-se por humanização a característica de tornar-se um ser social a partir de determinadas relações de poder que nos sujeitamos para que seja possível viver em sociedade.

Como demarca Carlos Noguera-Ramíres (2009) as necessidades sociais desde o século XVII foram condições de possibilidade para que a noção de uma educação pluralizada em diferentes espaços e artefatos que requerem dos sujeitos uma postura de constantes aprendizes. A emergência de uma sociedade da aprendizagem, como denomina o autor, posiciona a cultura como fator educacional com objetivo definido na circulação e produção de significados e sentidos na sociedade.

A sociedade de múltiplos espaços de formação e circulação de saberes que atualmente vivemos não é entendida aqui por um inatismo histórico, mas estudada a partir do que Michel Foucault (2015 b) compreende por proveniência. Para o filósofo a proveniência trata-se de um modo de pesquisa que analisa a proliferação e dispersão dos acontecimentos que subsidiaram a possibilidade de emergir um objeto em um determinado momento histórico. A conceituação de proveniência, portanto, "[...] é entendida como uma investigação que não busca terrenos firmes, senão areias movediças, fragmentos, omissões e incoerências que haviam sido deixados de fora pela história tradicional” (VEIGA-NETO, 2011, p. 60).

Uma abordagem histórica que não visa procurar os fundamentos originários, mas olhar para a exterioridade das práticas discursivas entrelaçadas às relações de poder que possibilitam a emergência do seu objeto, não seria passível de realizar-se em poucas páginas, como as de um artigo, esta análise necessita de aprofundamento e é isso que procuro na Tese de Carlos Noguera-Ramíres (2009).

Para o autor, ao realizar o esboço de uma genealogia da pedagogia e da educação, houve três modos de se pensar a educação na modernidade. As movimentações pedagógicas e 
educacionais dos séculos XVII e XVII firmam-se nos ideais da sociedade de ensino. Vemos formar-se o papel atribuído a quem ensina, a partir do caráter pedagógico com que o conhecimento é tomado. A necessidade de formar a individualidade de cada sujeito para o fortalecimento do Estado vai ter maior relevância no final do século XVI em que há a proliferação de instituições em diferentes instâncias educadoras. É nesta sociedade educadora que a pedagogia é legitimada enquanto ciência. Na produção de saberes especializados é que vão sendo determinadas as práticas discursivas que compõem a escola moderna, conhecida por seus métodos ditos atualmente como tradicionais, e por isso, concebidos como antiquados. Nos acontecimentos da sociedade de ensino e da educadora é possível perceber a atualização enunciativa que atravessa a educação e a pedagogia desde meados do século XVII.

Seguindo um viés cronológico da história poderíamos pensar que Comenius (NARODOWSKI , 2006) ao defender a ideia de que a escola deveria estar ao alcance de todos ao defender a compreensão de que o ser humano capaz de aprender todo e qualquer conhecimento, já anunciava características de uma Sociedade da aprendizagem em meados do século XVII. Isso seria possível se desconsiderarmos as condições exteriores as proposições de Comenius, as relações de saber-poder estabelecidas no século XVII pairavam sob o viés da necessidade de institucionalizar e categorizar as práticas educativas. Não se tratava de considerar a capacidade humana de produzir aprendizagens, mas sim as habilidades necessárias para ensinar e aprender, mas sim, de delimitar modos de ensino totalitários e eficazes, capazes de atingir a todos os sujeitos.

O que podemos perceber na concepção comeniana são as regularidades e as dispersões enunciativas que possibilitaram a emergência de uma prática discursiva que enuncia a compreensão de um sujeito biologicamente capaz de permanecer em constante aprendizagem. Tal visão coloca tanto a pedagogia, quanto a educação o desafio de convencer por meio de saberes disseminados em diferentes espaços e artefatos que nos ensinam certas "verdades" necessárias á população.

A cultura entendida como parte do processo educativo potencializa a Pedagogia Cultural como um conceito não só aceito, como também necessário de ser pensado e utilizado. Levando em conta o ponto de vista de Carlos Noguera-Ramíres (2009, p. 231) em que "Aprender ao longo da vida, aprender a aprender é a divisa do governamento contemporâneo". Atribui-se à educação a finalidade de perpetuar modos de fazer com que determinados saberes necessários à governamentalidade da população circulem como 
"verdades", sobrepondo à pedagogia a intencionalidade de produzir uma forma precisa de ser sujeito.

Nas interações socioambientais buscamos direcionamos nosso olhar para as relações que sustentam na atualidade a indispensabilidade de atuar no meio ambiente como meio de garantir o bem-estar da população. Em que marca nessa sociedade de múltiplos espaços de aprendizagem, meios de governamento através de propagandas circulantes na mídia.

Estamos diante de uma exigência constante da pedagogia de atualizar-se e fazer-se presente em todos os momentos da vida. Desde a primeira infância até a terceira idade há a produção de artefatos culturais para alcançar diferentes populações. $\mathrm{O}$ fato é que não há como escapar da condição de constantes aprendizes. Livros didáticos, histórias em quadrinhos, revistas de ampla circulação, cinema, televisão, internet, propagandas, jogos, etc., todos instrumentos que nos indicam atitudes e pensamentos, que muitas vezes adotamos por tratarse de saberes fabricados nos emaranhados das relações de poder.

Mediante o alvo desse artigo de mostrar como os saberes produzidos e disseminados nas campanhas publicitárias, destinadas à redução dos criadouros do mosquito Aedes aegypti, são medidas de governamento que incidem sobre as relações que estabelecemos com o meio ambiente para a segurança da população, passamos a demarcar cada uma das propagandas, mostrando o quanto essas nos fazem pensar na produtividade educativa desse artefato cultural.

Os artefatos midiáticos individualmente desmembrados e analisados nas próximas páginas possuem algumas regularidades no que diz respeito aos saberes que disseminam, quanto à globalização dos sujeitos a serem atingidos e a insistência em enfatizar as ações individuais no meio ambiente, como meio de garantir a segurança de toda a população brasileira. Parece-nos clara a afirmativa de que o conjunto de saberes circulantes nas propagandas está embasado na intencionalidade de orientar as condutas dos sujeitos como forma do Estado, quase que imperceptível, governar a população. Está aí à produtividade das propagandas que se dedicam a ensinar formas ditas como corretas de agir no meio ambiente.

A propaganda "Pior que água parada, é você parado" carrega a marca de uma empresa de bebidas disseminada em 17 países das Américas (AMBEV, 2016). No excerto "O time da AMBEV já está fazendo a sua parte, propagandas vão dar lugar a cartazes informativos. Assim como este comercial, que era para ter um dos produtos da AMBEV, mas deu espaço para este movimento" (AMBEV, 2016) podemos perceber que a posição da empresa pauta-se 
na disseminação de condutas que devem ser tomadas pela população. A pauta está na conscientização e convocação da população para atentar sobre a necessidade de cuidar do entorno para a eliminação dos criadouros do mosquito que afeta a redução de sua proliferação

Afirmativa apresentada com clareza na enunciação "Vamos virar esse jogo, virando garrafas”. Percebe-se o chamamento da população, com base em verdades produzidas que ensinam sobre as formas entendidas como corretas de agir em torno do meio ambiente.

Nas propagadas analisadas ressaltamos as regularidades enunciativas quanto às condutas sobre o meio ambiente que devem ser tomadas pela população. As formas de agir no meio ambiente, seja em espaços públicos ou privados, a partir do que mostram os artefatos, não são aleatórias, mas fabricadas por estudos científicos que explicam os processos de procriação do mosquito Aedes aegypti.

Tais artefatos valem-se dos estudos científicos para produzir verdades sobre os malefícios do mosquito e as atitudes e comportamentos corretos que devemos seguir para sobrevivência saudável da espécie humana. A partir dos estudos de Foucault (2015, p. 54 b) tem-se entendido o conceito de verdade como "um conjunto de procedimentos regulados para a produção, a lei, a repartição, a circulação e o funcionamento dos enunciados”. Desse conceito decorre que, por meio de relações específicas de poder, alguns saberes são legitimados como verdadeiros e outros como falsos.

Ligada ao discurso científico, a verdade está atrelada a procedimentos específicos de produção. Fabricar verdades não se pauta em ideias utópicas, mas em teses produzidas em meio a relações de poder que as sustentam e as tornam circulantes.

As verdades que circulam nas propagandas são meios de conduzir os sujeitos para o que é necessário à população. Nesse contexto social a Pedagogia se reinventa para pluralizarse e tornar-se flexível nos espaços e tempos de aprendizagem. A atual condição da "sociedade de aprendizagem" demarcada por Carlos Noguera-Ramíres (2009) atribui à Pedagogia um traço incessante de formar condutas, acionando-a constantemente a inferir na relação entre os ensinamentos e a formação dos sujeitos.

Como apresenta a autora Bárbara Garré (2015) as enunciações da mídia impressa embasam-se no discurso de crise ambiental para educar e ensinar os sujeitos atitudes entendidas como sustentáveis e, por isso, corretas de relacionar-se com o meio ambiente, mesmo que, muitas vezes, através do medo de catástrofes ambientais. 
É claro que entre as enunciações da mídia impressa e da mídia digital os endereçamentos dos corpus empíricos selecionados se distinguem. Contudo, estes dois artefatos culturais incidem, partindo de objetivos diferentes, nas relações socioambientais reguladas pelos conhecimentos científicos que ora apresentam a possibilidade de catástrofes ambientais, ora a preocupação com a saúde da população.

$\mathrm{Na}$ intencionalidade de constituir sujeitos no embate de diferentes interesses é que "Uma vontade de pedagogia que se imiscui, se imbrica e funciona ao procurar que sejamos produzidos a partir de aprendizados que atravessam cada vontade específica, as quais cruzam um determinado espaço e fazem operar, ali, uma configuração peculiar da pedagogia" (CAMOZZATO \& COSTA, 2013, p. 32) [grifo do original]. No entrelaçar desse conceito é inescusável compreender as dinâmicas que sustentam essa vontade de pedagogia, sinalizada pelas autoras, visíveis em diferentes artefatos e espaços.

A campanha "Zika Zero", ligada ao Ministério da Saúde, embasa-se igualmente nos saberes científicos que concluíram a relação entre a contaminação de gestantes pelo Zika vírus com o aumento de casos de bebês que nasceram com microcefalia, para alertar a sociedade. A proteção de gestantes e bebês está na organização e limpeza dos ambientes, apresentadas na propaganda por meio de imagem que representam uma variedade de espaços e objetos, são eles: calhas de chuva, galões de água, tampa de garrafa depositada no chão, vasos de planta, pneus velhos, garrafas usadas, sacos de lixo e baldes plásticos (BRASIL, 2016 a).

Claramente a preocupação com os cuidados no meio ambiente, neste artefato, está em torno da contaminação de gestantes pelo Zika vírus transmitido através do Aedes aegypti. Todavia ainda que a propaganda esteja ligada aos cuidados com a saúde de bebês e gestantes, a proeminência, dessa, permanece na limpeza de recipientes que podem vir a ser possíveis criadouros. "80\% dos criadouros do mosquito estão nas residências" (BRASIL, 2016 a). O uso da estatística mostra a necessidade de buscar uma maneira de produzir estimativas, através de relações de saber/poder que direcionam os indivíduos para a prática de ações no meio ambiente produzidas na esfera científica.

\footnotetext{
Ora, tenho a impressão de que existe, e tentei fazê-la aparecer, uma perpétua articulação do poder com o saber e do saber com o poder. Não podemos nos contentar em dizer que o poder tem a necessidade de tal ou tal descoberta, desta ou daquela forma de saber, mas que exercer o poder cria objetos de saber, os faz emergir, acumula informações e as utiliza. Não se pode compreender nada sobre o saber econômico se não se sabe como se exercia, quotidianamente, o poder, e o poder econômico. O exercício do poder cria perpetuamente saber e, inversamente, o saber acarreta efeitos de poder (FOUCAULT, 2015, p. 230 e 231).
} 
A utilização da estatística enquanto campo científico, sinalizando os locais onde se encontram maior incidência de criadouros é útil no momento em que legitima o discurso, promovendo a necessidade de ações individuais que refletem no coletivo da sociedade. A propaganda, com campos de saber tomados pela ciência nos seduz e convence da indispensabilidade de agir no meio ambiente para nossa segurança. Nisso vemos a produção de saberes que ensinam quais os comportamentos corretos para eliminar o mosquito em suas casas e nas residências próximas, traduzindo saberes científicos complexos em linguagem cotidiana, possíveis em práticas caseiras.

No firmamento das práticas de governamento a estatística torna-se uma ciência imprescindível para a realização todos os cálculos pertinentes sobre os acontecimentos relacionados à população. Percebe-se, a partir da utilização desta estratégia que os seres humanos agregados possuem fenômenos específicos. Debruçando-se sobre estes fenômenos referentes à população que o Estado constituiu um saber de governo.

\footnotetext{
A estatística mostra igualmente que a população comporta efeitos próprios da sua agregação e que esses fenômenos são irredutíveis aos da família: serão as grandes epidemias, as expansões epidêmicas, a espiral do trabalho e da riqueza. A estatística mostra [também] que, por seus deslocamentos, por seus modos de agir, por sua atividade, a população tem efeitos econômicos específicos (FOUCAULT, 2008, p. 138).
}

O uso da estatística na propaganda revela o meio de governar os sujeitos no exercício das relações de saber-poder. A produção de verdades, relacionadas ao mosquito buscam explicar seus processos de reprodução nos criadouros. Os estudos sobre as características biológicas do Aedes aegypti são apresentadas nesse artefato enquanto números que comprovam a grande presença de criadouros nas residências, mostrando a veracidade da necessidade de agirmos no meio ambiente, para que este seja um lugar seguro para a saúde da população.

Nos atravessamentos que constituem a dicotomia do que é verdadeiro e do que é falso, do que é aceito e do que deve ser negado, são as relações de saber-poder que possibilitam a construção teórica e conceitual sempre em movimento pelas contradições. Para compreender essas relações precisamos considerar que "[...] poder e saber estão diretamente implicados; que não há relação de poder sem constituição correlata de um campo de saber, nem saber que não suponha e não constitua ao mesmo tempo relações de poder" (FOUCAULT, 2013, p. 30). A articulação do saber apoiado na estatística coloca em funcionamento relações de poder que produzem e legitimam verdades acerca de como agir no meio ambiente prevendo os riscos da 
epidemia, suscitada pelo alto índice de criadouros do Aedes aegypt, que podem afetar a população.

O cálculo que comprova a relevância dos sujeitos em atuarem em prol da campanha contra o mosquito é universalizado quando nos alerta sobre a presença do Aedes aegypti nas residências. Essa marca moderna que carregamos está ligada a concepções, como a cartesiana e baconiana, que posicionam o ser humano como superior ao meio ambiente por sua racionalidade. Nas teias dessa ciência, categorizamos, classificamos, ditamos as regras para representar o meio ambiente e as melhores condições para sua preservação. Posição que firma atualmente o antropocentrismo na relação entre ser humano e meio ambiente.

Estamos abarcados por uma episteme moderna, esse "dispositivo estratégico" funciona orientado por princípios que negam ou aceitam as verdades, sustentando os saberes cientificamente válidos para serem socialmente aceitos (Foucault, 2015 a). Sendo assim, é possível compreender que as verdades são legitimadas pela episteme nas relações de saberpoder, assim como, são responsáveis por sustentá-la.

No entendimento de que as interações entre os seres humanos com o meio ambiente, a natureza e os animais estão alicerçadas na centralidade do que a sociedade representa classifica e necessita, é possível afirmar que esta relação está positivada no solo do antropocentrismo. Sendo assim, "Todas essas variantes antropocêntricas têm em comum a crença de que a superioridade humana funda-se no logos, na sua racionalidade e na sua linguagem" (FEITOSA, 2011, p. 85).

As condições que se fundam à episteme moderna e a visão de superioridade humana por sua racionalidade, cabe refletirmos sobre o quanto aceitamos determinadas condutas perante o meio ambiente por serem argumentadas com justificativas tão essenciais como a sobrevivência da espécie humana. A extinção de um inseto é válida quando nosso bem-estar está ameaçado. Tanto os preceitos das campanhas contra o mosquito Aedes aegypti, quanto o discurso da crise ambiental perpassam a indiscutível sobrevivência humana.

$\mathrm{Na}$ linha que segue este artigo as autoras Clarissa Henning, Marisa Luvielmo e Paula Henning (2010) ao direcionarem seus estudos para propagação da crise ambiental na mídia, evidenciam, nas campanhas publicitárias de conscientização ambiental, os atravessamentos entre o Biopoder e a Educação Ambiental. É sinalizado nos artefatos analisados estratégias de seguridade, já que interpela os sujeitos para que esses pensem no futuro do Planeta interrompendo a crise ecológica. 
O biopoder é entendido como uma tecnologia de poder que investe sobre o corpoespécie, preocupado com a gestão sobre a vida da população a partir de sua seguridade com vistas no seu futuro (FOUCAULT, 2010). Nas campanhas publicitárias cujo foco encontra-se na eliminação dos possíveis criadouros do mosquito, na justificativa de que esse é transmissor de doenças como a dengue, a chikungunya e o vírus Zika, atualmente considerado pela ciência causador da microcefalia em bebês, percebem-se o biopoder operando na regulação e estabilidade da saúde dos indivíduos. Para que o governamento se efetue também se faz necessário a construção de estratégias de controle para a prevenção, segurança e regulação das condutas da massa da população.

Em conformidade com as problematizações trazidas pelas autoras Clarissa Henning, Marisa Luvielmo e Paula Henning (2010), considera-se a Educação Ambiental parte das estratégias de controle da população. Os saberes desse campo regulam as condutas dos sujeitos tanto na esfera individual, quanto coletiva, buscando mobilizar atitudes em prol do meio ambiente.

Conveniada à campanha "Zika Zero" a propaganda "Mobilização dos estudantes contra o vírus zika" (BRASIL, 2016 b) conta com a parceria do Ministério da Educação. O objetivo é trazer para o âmbito escolar a problemática do combate ao Aedes aegypti, incidindo com maior ênfase nos sujeitos infantis. É clara a insistência em trazer as práticas de limpeza nos espaços residenciais e em torno de seus bairros. Fala-se no cuidado com os espaços individuais, mas também coletivos, como por exemplo, em praças e nas demais residências das comunidades. A expressão "Vamos fazer uma faxina!" (BRASIL, 2016 b), presente na propaganda, retrata a convocação de todos para agirem no meio ambiente. Evidenciando a solicitude de estender-se, ao mesmo tempo, pela formação de condutas individuais e sociais. Professores, gestantes, mulheres, homens, crianças, pais, médicos, etc, todos são chamados a agirem na extinção do mosquito para o bem comum. Somos todos culpados e agentes da solução para a problemática já a muito recorrente no Brasil.

$\mathrm{Na}$ propaganda descrita acima é relevante sinalizar as regularidades enunciativas que aparecem nas enunciações referentes à crise ambiental e a limpeza de espaços particulares e públicos. Nas enunciações descritas abaixo deparamo-nos com o convite de aderirmos ao combate contra o Aedes aegypti, vejamos: "Tem Revolução que começa nas ruas, essa vai começar dentro de casa" (AMBEV, 2016). "Faça a sua parte. Vamos destruir o mosquito" (BRASIL, 2016 a). "Vamos para as ruas, de casa em casa, informar e pedir ajuda para combater o mosquito" (BRASIL, 2016 b). 
O ser humano nas três propagandas é colocado como a figura capaz de solucionar, ou ao menos amenizar, as consequências de suas próprias ações. Nas práticas de conscientização ambiental, no caso da crise ambiental ou adotando a postura de se engajar na campanha contra o mosquito é o ser humano em suas relações sociais e ambientais que é convocado a assumir condutas que prezam pelo bem-estar coletivo.

No direcionamento das condutas dos sujeitos há a interpelação desses no ambiente, entendido como um conjunto de dados naturais e sociais. Como nos mostra Edson Luiz Lindner (2012, p. 14) o ambiente constitui-se de um...

[...] sistema que envolve uma comunidade de pessoas, com sua parte física, em que está inserido o ambiente natural no qual os seres humanos interagem com os demais componentes vivos e não vivos; a parte socioeconômica na qual se observam todas as relações de produção e consumo de bens materiais e de capital; a parte cultural na qual estão inseridas as tradições, os costumes, as normas de coexistência e a vivência de valores; e por fim, a parte política na qual o exercício da cidadania deve orientar as ações e as tomadas de decisões.

Partindo da conceituação de ambiente, escrita por Lindner (2012), podemos pensar em algumas temáticas produzidas pelo campo da Educação Ambiental enquanto modos de colocar em funcionamento o governamento das condutas dos sujeitos, através da relação que se estabelece entre os seres humanos e as "coisas", como o ambiente. Essa relação a que Michel Foucault (2015, p. 415 b) se refere, entre outras condições descritas pelo autor, “[...] são o costume, os hábitos, as formas de agir e pensar etc.; finalmente, os homens em suas relações com outras coisas ainda que sejam os acidentes ou as desgraças como a fome, a epidemia, a morte etc." Ao passo daquilo que interessa ao governo, no material empírico analisado ressalta-se, a regulação das epidemias principalmente no que diz respeito à dengue e à microcefalia causada pelo vírus Zika, e as formas de agir e pensar sobre o meio ambiente quando incidem sobre a necessidade de verificá-lo, organizá-lo e limpá-lo para a eliminação das condições propícias a reprodução do mosquito.

$\mathrm{Na}$ passagem do território enquanto elemento primordial do Estado para a complexidade dos processos pertencentes às relações dos sujeitos com alguém ou com algo se vê emergir a população e a necessidade de seu governamento. Tal premência atenta para o aumento e manutenção de sua riqueza e bem-estar e embasa-se no estudo de todos os seus processos constituindo, por conseguinte, a ciência do governo. A população, por assim dizer, ao mesmo tempo necessita ser gerenciada ao passo que é objeto do governo. Pode-se então compreender por governamentalidade:

[...] o conjunto constituído pelas instituições, os procedimentos, analises e reflexões, os cálculos e as táticas que permitem exercer essa forma bem específica, embora 
muito complexa, de poder que tem por alvo principal a população, por principal forma de saber a economia política e por instrumento técnico essencial os dispositivos de segurança (FOUCAULT, 2008, p. 143).

A inferência no meio ambiente, ressaltada nos artefatos midiáticos analisados, traz a alusão de que este não só se faz de um conjunto de elementos naturais, mas constitui-se na interação com a cultura. Concepção de ambiente embasada na interação entre as condições ecossistêmicas e socioambientais.

Voltada à educação dos sujeitos no que concerne às questões ambientais o campo da Educação Ambiental vai cada vez mais ganhando força e foco na sociedade por meio também da circulação midiática. Na perspectiva dos Estudos Culturais, a cultura, em constante movimento social, estabelece um conjunto de relações e práticas fundamentais para a consolidação dos discursos voltados às questões ambientais (WORTMANN, 2010). Esses, por estarem em grande circulação, distribuídos em diferentes artefatos midiáticos têm sua produtividade na formação de representações sobre o que se entende por meio ambiente, indicando modos de nos relacionarmos para a preservação tanto do meio natural quanto social.

A Educação Ambiental esteve presente em toda a escrita deste artigo, talvez não da forma a sugerir ou criticar ações, mas esteve como campo político de problematizações. A Educação Ambiental, aqui, não esteve envolta da vertente conservacionista na defesa da reciclagem dos pneus e garrafas citadas nas propagandas, ou da teorização crítica em ver na posição do educador ambiental a figura de um mediador da transformação social a partir da discussão a respeito dos meios de produção capitalista. Ela esteve em posição de apresentar as múltiplas possibilidades de nos constituirmos sujeitos ambientais na produção de saberes disseminados nos artefatos culturais. A Educação Ambiental se alicerçou na vertente pósestruturalista para mostrar as estratégias e saberes utilizados pelo Estado governamentalizado que enxerga na relação dos sujeitos com as coisas ou com outros seres, meios de governamento da população como garantia da sobrevivência e bem-estar dos seres humanos.

\section{CONSIDERAÇÕES FINAIS}

A contemporaneidade nos exige a posição de constantes aprendizes, somos frequentemente interpelados por pedagogias que estabelecem conjuntos de saberes e práticas necessárias à formação de condutas definidas como garantia de bem-estar da população. Neste cenário o conceito de Pedagogia Cultural convida-nos a pensar e colocar sob exame os saberes disseminados e produzidos nos mais variados artefatos culturais 
A urgência social que se instaurou no país através da epidemia de doenças transmitidas pelo mosquito Aedes aegypti - dengue, zika e chikungunya - incide nas minúcias da ação dos sujeitos que repercutem no meio ambiente por intermédio enfático da eliminação ou, ao menos, diminuição dos criadouros do mosquito. Neste viés demarcou-se ao longo da escrita que a fabricação dos saberes legitimados e justificados na necessidade de buscar o bem-estar da população produz modos de educarmo-nos ambientalmente.

Ao longo do artigo tivemos a preocupação em apontar nas propagandas analisadas não só a necessária influição sobre o meio ambiente como técnica de seguridade, como igualmente apresentar a Pedagogia Cultural e a Educação Ambiental como traços da governamentalidade.

Foi possível sinalizar ainda as regularidades enunciativas entre as enunciações relacionadas à crise ecológica e às medidas de verificação e organização do meio ambiente a fim de impedir a reprodução do mosquito Aedes aegypti. Nessas vê-se a posição do homem como culpado e agente capaz de solucionar as problemáticas em que é intitulado como causador.

Os modos de constituição dos seres humanos estão enraizados na organização social e cultural que possui suas condições de possibilidade na história. A ideia de população e a preocupação do Estado em conhecer e fabricar verdades sobre seus fenômenos específicos possibilitou a condição da emergência de uma sociedade da aprendizagem como bem discorre Carlos Noguera-Ramíres (2009). A condição de flexibilidade da pedagogia está imersa nas relações de poder-saber que pluralizam os espaços de aprendizagens que exigem dos sujeitos a característica de constantes aprendizes. Nessas condições socioculturais contemporâneas delimitaram-se as técnicas e ciências que fundamentam a governamentalidade em que a extinção de um inseto em prol da manutenção e segurança da espécie humana não só é posta como justificável, mas também indispensável.

Nas propagandas as verdades fabricadas valem-se da legitimação do discurso científico para serem aceitas e, por isso, circulantes. A estatística apresenta-se, nessas, como ciência do governo que demarca a necessidade da população de atuar no meio ambiente, posto que o maior risco de proliferação do mosquito encontra-se nas residências. O convite a cada sujeito aparece como fundamental ao cuidado com os demais.

Olhar para outros modos produzir verdades que incidem, na maioria das vezes, nos modos de compreendermos e representarmos o meio ambiente nas linhas relacionais entre os 
aspectos ambientais e culturais, partindo de uma análise política do conceito de governamento, possibilita refletirmos sobre as necessidades indiscutíveis e universais.

A persistência das propagandas em acionar os sujeitos para o cuidado consigo e com a população, através da ação no meio ambiente provoca-nos a olhar para o conceito de Pedagogia Cultural e para a Educação Ambiental na contemporaneidade na qualidade de estratégias de controle da sociedade que viabilizam o governamento da população.

\section{REFERÊNCIAS:}

AMBEV. Pior que água parada é você parado. Disponível em: https://www.youtube.com/watch?v=zv58GBMX6IU. Acesso em: 22 dez. 2016

ANDRADE, Paula Deporte; COSTA, Marisa Vorraber. Usos e possibilidades do conceito de pedagogias culturais nas pesquisas em estudos culturais em educação. Textura, Canoas v. 17, n. 34, p. 48 - 63, mai./ago. 2015. Disponível em: http://www.periodicos.ulbra.br/index.php/txra/article/view/1501. Acesso em: 22 dez. 2016

BRASIL. Ministério da Saúde. Campanha Zika Zero. 2016. Disponível em: https://www.youtube.com/watch?v=TrECnGykCog. Acesso em: 22 dez. 2016 a

BRASIL. Ministério da Educação. Mobilização dos estudantes contra o vírus zika. 2016. Disponível em: https://www.youtube.com/watch?v=_ef_rbv-Dqw. Acesso em: $22 \mathrm{dez} .2016 \mathrm{~b}$

CAMOZZATO, Viviane Castro; COSTA, Marisa Vorraber. Vontade de Pedagogia Pluralização das pedagogias e condução dos sujeitos. In: Cadernos de Educação. N. 44. P. 22 - 44. Disponível em: https://periodicos.ufpel.edu.br/ojs2/index.php/caduc/issue/view/235. Acesso em: Acesso em: 22 dez. 2016

FEITOSA, Charles. O Silêncio dos Animais. In: LINS, Daniel; OLIVEIRA, Nilson; BARROS, Roberto (orgs.). Nietzsche/ Deleuze: Natureza/Cultura. 1 ed. São Paulo: Lumme Editor, 2011.

FOUCAULT, Michel. Segurança, Território e População: Curso dado no College de France (1977-1978). São Paulo: Martins Fontes, 2008.

. Em defesa da sociedade: Curso dado no College de France (1975-1976). 2 ed. São Paulo: Martins Fontes, 2010.

. Vigiar e Punir: nascimento da prisão. 41 ed. Petrópolis: Vozes, 2013.

. Arqueologia do Saber. $8^{\text {a }}$. Ed. Rio de Janeiro: Forense Universitária, 2015a.

. Microfísica do poder. 2 ed. Rio de Janeiro: Paz e Terra, 2015 b.

GARRÉ, Bárbara Hees. O dispositivo da Educação Ambiental: modos de constituir-se sujeito na revista Veja. Rio Grande, 2015. 185 f. Tese (Doutorado em Educação Ambiental) Universidade Federal do Rio Grande. Programa de Pós-Graduação em Educação Ambiental.

GODOY, Ana. O modelo da Natureza e a Natureza do modelo. In: São Paulo em Perspectiva. Vol 14. 2000. Disponível em: http://dx.doi.org/10.1590/S010288392000000400015. Acesso em: 22 dez. 2016

GUATTARI, Félix. As três ecologias. $21^{\mathrm{a}}$ ed. Campinas: Papirus, 2012. 
GUIMARÃES, Leandro Belinaso; SAMPAIO, Shaula Maria Vicentini. Praticando Estudos Culturais em articulação com a Educação Ambiental. In: ZAKRZEVSKI, Sônia Balvedi; BARCELOS, Valdo. (Orgs.). Educação Ambiental e Compromisso Social. Erechim: EdiFAPES, 2004. P. 125 - 146.

GUIMARÃES, Leandro Belinaso. Imagens da sustentabilidade em um mundo sem ilhas. In: HENNING, Paula; RIBEIRO, Paula Regina; SCHMIDT, Elisabeth (Org.). Perspectivas de investigação no campo da educação ambiental \& educação em ciências. Rio Grande: FURG, 2011.

HENNING, Clarissa Corrêa; LUVIELMO, Marisa de Mello; HENNING, Paula Corrêa. Meio Ambiente, prevenção e Seguridade: "A Hora do Planeta" sob análise. In: HENNIG, Paula Corrêa; GARRÉ, Bárbara Hees; LUVIELMO, Marisa de Mello (org). Biopolítica e Governamentalidade: modos de fazer e gerenciar a educação contemporânea. Rio Grande: FURG, 2010.

HENNING, Paula Corrêa. Provocações para este tempo... a educação ambiental e os atravessamentos midiáticos. In: PREVE, Ana Maria Hoerperset et. al. (orgs.). Ecologias inventivas: conversas sobre educação. Santa cruz do Sul, RS: EDUNISC, 2012.

LINDNER, Edson Luiz. Refletindo sobre o ambiente. In: LISBOA, Cassiano Pamplona; KINDEL, Eunice Aita Isaia (org). Educação Ambiental: da teoria à prática. Porto Alegre: Mediação, 2012

NOGUERA-RAMÍREZ, Carlos Ernesto. O governamento pedagógico: da sociedade do ensino para a sociedade da aprendizagem. Porto Alegre, 2009. $266 \mathrm{f}$. Tese (Doutorado em Educação) - Universidade Federal do Rio Grande do Sul. Faculdade de Educação. Programa de Pós-Graduação em Educação.

REIGOTA, Marcos. O que é Educação Ambiental. 2a ed. São Paulo: Brasiliense, 2014.

VEIGA-NETO, Alfredo. Coisa do governo... In: RAGO, Margareth; ORLANDI, Luiz B. Lacerda; VEIGA-NETO, Alfredo. Imagens de Foucault e Deleuze: ressonâncias nietzschianas. 2 ed. Rio de Janeiro: DP\&A, 2005. P. 13 - 34.

Foucault \& a educação. $3^{\text {a }}$ ed. Belo Horizonte: Autêntica, 2011.

WORTMANN, Maria Lúcia Castagna. A Educação Ambiental em perspectivas culturalistas. In.: CALlONI, H. e SILVA, P.R.G.C. (org). Contribuições à Educação Ambiental. Pelotas: Editora Universitária/UFPel, 2010. p. 13-37.

Por que se valer do cinema, da mídia, da literatura, da televisão para discutir a natureza/ambiente? In: ZAKRZEVSKI, Sônia Balvedi; BARCELOS, Valdo. (Org). Educação Ambiental e Compromisso Social. Erechim: EdiFAPES, 2004. p. 147-161. 